
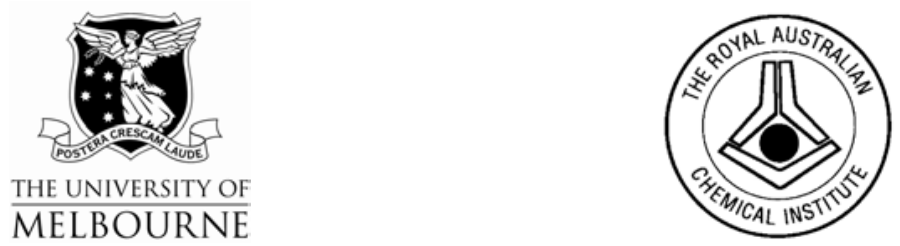

molecules

ISSN 1420-3049

http://www.mdpi.org

\title{
Self-Terminating, Oxidative Radical Cyclizations
}

\author{
Tim Dreessen ${ }^{2}$, Christian Jargstorff ${ }^{2}$, Lars Lietzau ${ }^{2}$, Christian Plath ${ }^{2}$, Arne Stademann ${ }^{2}$ and \\ Uta Wille ${ }^{1, *}$ \\ ${ }^{1}$ School of Chemistry, The University of Melbourne, Victoria 3010, Australia. Tel. $(+61) 38344$ \\ 7622, Fax (+61) 39347 5180, e-mail uwille@unimelb.edu.au. \\ ${ }^{2}$ Institut für Organische Chemie, Universität Kiel, Olshausenstr. 40, 24098 Kiel, Germany.
}

Received: 23 February 2004 / Accepted: 1 March 2004 / Published: 31 May 2004

\begin{abstract}
The recently discovered novel concept of self-terminating, oxidative radical cyclizations, through which alkynes can be converted into carbonyl compounds under very mild reaction conditions using $O$-centered inorganic and organic radicals as oxidants, is described
\end{abstract}

Keywords: Radical reactions, $O$-centered radicals, cyclizations, oxidations.

\section{Introduction}

During the past 20-30 years radical reactions became an important synthetic tool, especially for the synthesis of complicated, often polycyclic molecules. The success of this methodology is a result of (i) the mostly excellent stereoselectivities of these reactions [1], and (ii) the downright ease of radical generation and radical chain maintaining by using the combination of alkyl halides (or thiols, selenides, nitro compounds, etc.) with transition metal or non-metal hydrides (generally tin, mercury or silicon compounds) as radical precursors [2,3]. However, this advantage can turn into a serious disadvantage, if the difficulty to remove the toxic tin or mercury compounds from the reaction mixture is considered. The demand for non-toxic alternatives is therefore steadily increasing, and meanwhile many interesting new concepts were reported in literature [4-8]. 
Whereas the reactions involving $C$-centered radicals dominated this field for a long time, heteroatom-centered radicals came to the fore only latterly. Of these, the $O$-centered alkoxyl radicals, $\mathrm{RO}$, have been especially intensively studied, and their intramolecular addition (cyclization) to $\mathrm{C}=\mathrm{C}$ double bonds is a very versatile $\mathrm{C}-\mathrm{O}$ bond forming reaction to yield oxygen containing heterocycles $[9,10]$. In contrast to this, intermolecular addition reactions of $O$-centered radicals, other than molecular oxygen, to $\pi$ systems have as yet received considerably less attention [11-13]. This is due to side-reactions in these radicals, e.g. hydrogen atom transfer (HAT) from the allylic position or $\beta$ fragmentation in $\mathrm{RO}^{\bullet}$, which are both faster than radical addition [14]. The $\mathrm{C} \equiv \mathrm{C}$ triple bond as radical acceptor is only well established in intramolecular additions of $C$-centered radicals, whereas the frequent failure of intermolecular radical additions is explained by disfavored interactions of the involved orbitals [2,14]. A new synthetic method, which both allows the selective oxidation of alkynes combined with the advantages of radical chemistry, for example mild conditions and high stereoselectivities, and which is also in compliance with the requirements that non-toxic reagents should be used, seems to be highly desirable.

Our concept to approach this problem consisted of replacing the organic part in "RO" by an inorganic residue " $\mathrm{X}$ " $(\mathrm{RO} \bullet \rightarrow \mathrm{XO} \bullet$, which does not contain carbon, but instead N, S or H. Examples for this purpose are the nitrate radical, $\mathrm{NO}_{3}{ }^{\bullet}$, the sulfate radical anion, $\mathrm{SO}_{4}{ }^{-}$, and the hydroxyl radical, $\mathrm{HO}^{\bullet}$, (with $\mathrm{X}=\mathrm{NO}_{2}, \mathrm{SO}_{3}^{-}, \mathrm{H}$ ), respectively. Unlike $\mathrm{RO}^{\bullet}$, these radicals cannot undergo simple $\beta$ fragmentations, because no stable leaving groups may be formed. Because of the lack of carbon atoms, $\mathrm{NO}_{3} \bullet, \mathrm{SO}_{4}{ }^{-}$and $\mathrm{HO}^{\bullet}$ can be regarded as "inorganic" radicals.

Inorganic radicals have so far led a relatively shadowy existence in organic synthesis. Famous exceptions are the radical chain chlorinations and brominations, which are used for the synthesis of halogenated hydrocarbons [15]. Autoxidation processes with molecular oxygen, which is in its triplet ground state also is an inorganic radical species, involve the formation of peroxyl and alkoxyl radicals as intermediates and are of significant importance for the industrial synthesis of several bulk chemicals, for example for the manufacture of phenol and acetone from cumene by the Hock process [16].

\section{Results and Discussion}

Free-radical addition to $\mathrm{C} \equiv \mathrm{C}$ triple bonds leads to formation of very reactive vinyl radicals. In order to reduce the amount of possible products, which is essential for the study of new reactions, the subsequent reactions of these vinyl radical intermediates can be forced to proceed intramolecularly through incorporation of the alkyne unit into a medium-sized ring. Due to their strong transannular interactions, medium cycloalkynes $(n=8-12)$ are very useful and easily accessible model compounds [17], which were employed by us to explore the scope and limitations of the reactions with $\mathrm{NO}_{3}{ }^{\circ}$, $\mathrm{SO}_{4}{ }^{\bullet-}$ and $\mathrm{HO}^{\bullet}$, respectively. 


\section{Inorganic Radicals}

$\mathbf{N O}_{3}{ }^{\bullet}$ Radicals: $\mathrm{NO}_{3}{ }^{\bullet}$ is an important night-time atmospheric oxidant, which can react with organic compounds via several pathways, i.e. by HAT, electron transfer or addition to $\pi$ systems. On average, the unpaired electron is located on oxygen so that $\mathrm{NO}_{3}{ }^{\bullet}$ reacts as an $O$-centered radical species. However, despite its broad chemical versatility, only relatively few examples on the application of $\mathrm{NO}_{3}{ }^{\bullet}$ as reagent in organic synthesis existed in the literature [18-28]. Generation of $\mathrm{NO}_{3}{ }^{\bullet}$ in solution and on a preparative scale from non-toxic precursors can be performed by either anodic oxidation of inorganic nitrates (Scheme 1.1) or by photo-induced electron transfer from ceric(IV) ammonium nitrate, CAN (Scheme 1.2) [18-28].

\section{Scheme 1}
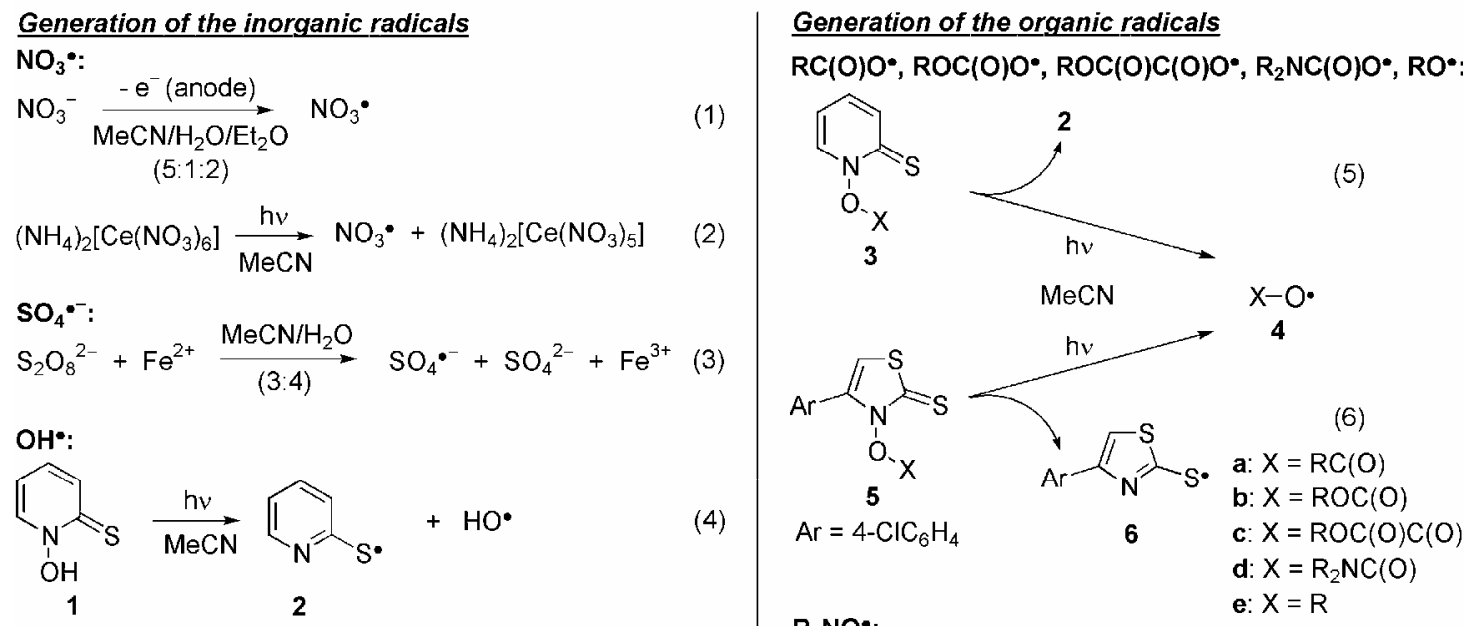

$\mathrm{R}_{\mathbf{2}} \mathrm{NO}^{*}$ :

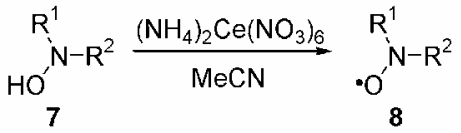

The reaction of $\mathrm{NO}_{3}{ }^{\bullet}$ with the medium-sized cycloalkynes 9 lead to oxidation of the compounds to yield the cis-fused bicyclic ketones $\mathbf{1 0}$ and $\mathbf{1 1}$ (Scheme 2 and Table 1, entries 1 and 2; $\mathrm{X}=\mathrm{NO}_{2}$ ) [29]. The assumed mechanism is shown in Scheme 3 for the exemplary reaction of $9 \mathbf{a}$.

Scheme 2

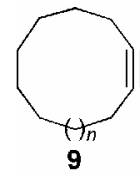

a: $n-1$

b: $n=3$<smiles>[Y][C@H](C)O[WH]([Y])C</smiles>

12

a: $i=1$

b: $i=2$

c: $i=3$

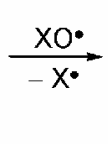

$\underset{x \cdot}{\stackrel{20}{\longrightarrow}}$<smiles>C=C1CCCC(=O)C2CCCC12</smiles>

a: $n-1$

b: $n=3$

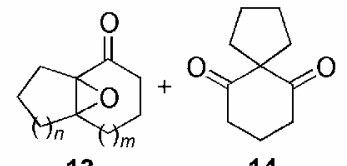

13

a: $n=m=1$

b: $n=1, m=2$

c: $n=2, m=1$

d: $n=2, m=1$

11<smiles>O=C1CCCC2CCCCC12</smiles>

\begin{tabular}{|c|c|c|}
\hline \multicolumn{3}{|c|}{ radicals $\mathrm{XO}^{\circ}$} \\
\hline inorganic & \multicolumn{2}{|c|}{ organic } \\
\hline $\mathrm{NO}_{3} \cdot \mathrm{X}=\mathrm{NO}_{2}$ & $\mathrm{RC}(\mathrm{O}) \mathrm{O}^{\bullet}$ & $\mathrm{X}=\mathrm{RC}(\mathrm{O})$ \\
\hline $\mathrm{SO}_{4}^{\bullet-}: \mathrm{X}=\mathrm{SO}_{3}^{-}$ & $\mathrm{ROC}(\mathrm{O}) \mathrm{O}^{*}$ & $X=\operatorname{ROC}(O)$ \\
\hline \multirow[t]{4}{*}{$\mathrm{OH}^{*}: \quad \mathrm{X}=\mathrm{H}$} & $\mathrm{ROC}(\mathrm{O}) \mathrm{C}(\mathrm{O}$ & $\mathrm{X}=\mathrm{ROC}(\mathrm{O}) \mathrm{C}(\mathrm{O})$ \\
\hline & $\mathrm{RO}^{\bullet}:$ & $X=R$ \\
\hline & $\mathrm{R}_{2} \mathrm{NC}(\mathrm{O}) \mathrm{O}^{\bullet}$ & $X=\mathrm{R}_{2} \mathrm{NC}(\mathrm{O})$ \\
\hline & $\mathrm{R}_{2} \mathrm{NO}^{\bullet}$ & $\mathrm{X}=\mathrm{R}_{2} \mathrm{~N}$ \\
\hline
\end{tabular}


Table 1. Yields of the reaction of medium-sized cycloalkynes 9 with inorganic and organic $O$-centered radicals $\mathrm{XO}^{\bullet}$.

\begin{tabular}{|c|c|c|c|}
\hline Entry & 9 & $\mathbf{X}$ & Yield (\%) \\
\hline 1 & $\mathbf{a}$ & $\mathrm{NO}_{2}^{[\mathrm{a}]}$ & 10a: $53,11: 17^{[b]}$ \\
\hline 2 & b & $\mathrm{NO}_{2}{ }^{[\mathrm{a}]}$ & $10 \mathrm{~b}: 35^{[\mathrm{b}, \mathrm{c}]}$ \\
\hline 3 & $\mathbf{a}$ & $\mathrm{SO}_{3}^{-}$ & 10a: $52,11: 27^{[\mathrm{d}]}$ \\
\hline 4 & $\mathbf{a}$ & $\mathrm{H}$ & $10 \mathbf{a}+11: 63^{[\mathrm{d}, \mathrm{e}]}$ \\
\hline 5 & a & $\mathrm{RC}(\mathrm{O}) ; \mathrm{R}=\mathrm{Me}^{[\mathrm{ff}]}$ & 10a: $35, \mathbf{1 1}: 31^{[\mathrm{d}, \mathrm{e}]}$ \\
\hline 6 & $\mathbf{a}$ & $\mathrm{RC}(\mathrm{O}) ; \mathrm{R}=\mathrm{C}_{6} \mathrm{H}_{5}^{[\mathrm{f}]}$ & 10a: $42, \mathbf{1 1}: 39^{[\mathrm{d}, \mathrm{e}]}$ \\
\hline 7 & $\mathbf{a}$ & $\mathrm{RC}(\mathrm{O}) ; \mathrm{R}=4-\mathrm{MeOC}_{6} \mathrm{H}_{4}^{[\mathrm{f}]}$ & 10a: $47, \mathbf{1 1}: 42^{[\mathrm{d}, \mathrm{e}]}$ \\
\hline 8 & $\mathbf{a}$ & $\mathrm{ROC}(\mathrm{O}) ; \mathrm{R}=\mathrm{Me}^{[\mathrm{ff}]}$ & $10 a+11: 94^{[\mathrm{d}, \mathrm{e}]}$ \\
\hline 9 & $\mathbf{a}$ & $\mathrm{ROC}(\mathrm{O}) ; \mathrm{R}=\mathrm{Me}^{[\mathrm{g}]}$ & $10 \mathbf{a}+11: 52^{[\mathrm{d}, \mathrm{e}]}$ \\
\hline 10 & $\mathbf{a}$ & $\operatorname{ROC}(\mathrm{O}) ; \mathrm{R}=$ Allyl $^{[\mathrm{f}]}$ & 10a $+11: 89^{[\mathrm{d}, \mathrm{e}]}$ \\
\hline 11 & $\mathbf{a}$ & $\mathrm{ROC}(\mathrm{O}) ; \mathrm{R}=\mathrm{C}_{6} \mathrm{H}_{5}^{[\mathrm{f}]}$ & $10 \mathbf{a}+11: 72^{[\mathrm{d}, \mathrm{e}]}$ \\
\hline 12 & $\mathbf{a}$ & $\mathrm{ROC}(\mathrm{O}) \mathrm{C}(\mathrm{O}) ; \mathrm{R}=\mathrm{Et}^{[\mathrm{ff}]}$ & $10 \mathbf{a}+11: 82^{[\mathrm{d}, \mathrm{e}]}$ \\
\hline 13 & $\mathbf{a}$ & $\mathrm{R}_{2} \mathrm{NC}(\mathrm{O}) ; \mathrm{R}=\mathrm{Et}^{[\mathrm{f]}]}$ & $10 a+11: 89^{[\mathrm{d}, \mathrm{e}]}$ \\
\hline 14 & $\mathbf{a}$ & $\mathrm{R}_{2} \mathrm{NC}(\mathrm{O}) ; \mathrm{R}=\mathrm{Et}^{[\mathrm{f}]}$ & $10 a+11: 69^{[b, e]}$ \\
\hline 15 & $\mathbf{a}$ & $\mathrm{R}_{2} \mathrm{NC}(\mathrm{O}) ; \mathrm{R}=\mathrm{Et}, \mathrm{C}_{6} \mathrm{H}_{5}^{[\mathrm{ff}]}$ & $10 \mathbf{a}+11: 58^{[\mathrm{d}, \mathrm{e}]}$ \\
\hline 16 & $\mathbf{a}$ & $\mathrm{R} ; \mathrm{R}=\mathrm{Me}^{[\mathrm{g}]}$ & $10 \mathbf{a}+11: 32^{[\mathrm{d}, \mathrm{e}]}$ \\
\hline 17 & $\mathbf{a}$ & $\mathrm{R}_{2} \mathrm{~N} ; \mathrm{R}, \mathrm{R}=-\mathrm{C}(\mathrm{O}) \mathrm{CH}_{2} \mathrm{CH}_{2} \mathrm{C}(\mathrm{O})-$ & $10 \mathbf{a}+11: 50^{[\mathrm{d}, \mathrm{e}, \mathrm{h}]}$ \\
\hline 18 & $\mathbf{a}$ & $\mathrm{R}_{2} \mathrm{~N} ; \mathrm{R}, \mathrm{R}=-\mathrm{C}(\mathrm{O})-2-\mathrm{C}_{6} \mathrm{H}_{4}-\mathrm{C}(\mathrm{O})-$ & 10a + 11: $27^{[\mathrm{d}, \mathrm{e}, \mathrm{h}]}$ \\
\hline
\end{tabular}

${ }^{[\mathrm{a}]}$ Electrogenerated $\mathrm{NO}_{3}{ }^{\bullet}$; ${ }^{[\mathrm{b}]}$ Preparative scale, isolated yield; ${ }^{[\mathrm{c}]}$ In addition, an inseparable mixture of various oxidation products $(36 \%)$ was also formed; ${ }^{[\mathrm{d}]}$ Analytical scale, GC yield with internal standard ( $n$-hexadecane); ${ }^{[\mathrm{e}]}$ Yield with regard to the radical precursor (see text); ${ }^{[\mathrm{f}]}$ Radical precursor 3; ${ }^{[\mathrm{g}]}$ Radical precursor 5;

${ }^{[\mathrm{h}]}$ Ultrasound treatment.

Scheme 3

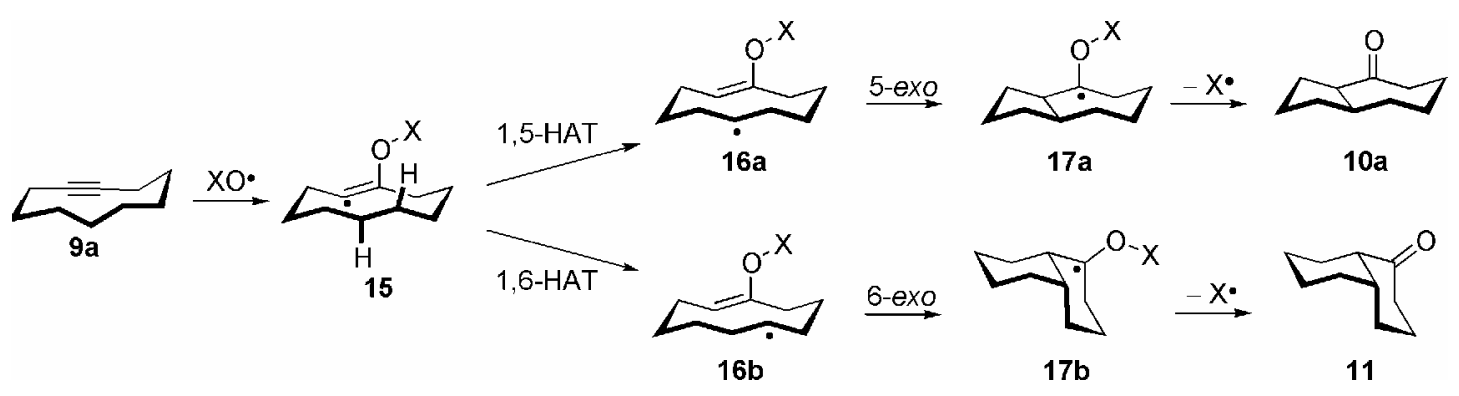


Initial formation of the vinylic radical $\mathbf{1 5}$ and subsequent hydrogen abstraction from a transannular activated methylene group (1,5- or 1,6-HAT, respectively) yields the secondary alkyl radicals 16a and 16b. These species may now cyclize to the remaining $\mathrm{C}=\mathrm{C}$ double bond in a 5-exo or 6-exo fashion, respectively [30]. The cyclization cascade is completed by fragmentation of the radicals $\mathbf{1 7} \mathbf{a} / \mathbf{b}$ along the weak $\mathrm{O}-\mathrm{N}$ bond under formation of the stable carbonyl bonds in the ketones 10a and $\mathbf{1 1}$ and release of $\mathrm{NO}_{2}{ }^{\bullet}$. The latter radical is far less reactive than $\mathrm{NO}_{3}{ }^{\bullet}$, and no interference by $\mathrm{NO}_{2}{ }^{\bullet}$, i.e. trapping of radical intermediates or initiation of a radical chain process, was ever observed. Because of the non-chain character, this cyclization cascade may be termed a "self-terminating, oxidative radical cyclization", in which $\mathrm{NO}_{3}{ }^{\bullet}$ formally has the role of an $\mathrm{O}$ atom synthon. The exclusive formation of the cis-fused bicycles is, according to AM1 calculations [29], due to the lower activation barrier of the cyclization $16 \mathbf{a} / \mathbf{b} \rightarrow \mathbf{1 7} \mathbf{a} / \mathbf{b}$ in this medium-sized ring, compared to $16 \mathbf{a} / \mathbf{b} \rightarrow$ trans $-17 \mathbf{a} / \mathbf{b}$, which is in accordance with the literature [1]. The concept of self-terminating radical oxygenations could also be extended to the cyclization of medium-sized rings possessing two $\pi$-systems [31]. The $\mathrm{NO}_{3}{ }^{\bullet}$ induced cyclization of the 5-cycloalkynones $\mathbf{1 2 a}$ and $\mathbf{1 2} \mathbf{b}$, respectively, lead to formation of the isomeric bicyclic epoxy ketones 13a-c in over 70\% total yield in each case $\left(\mathrm{X}=\mathrm{NO}_{2}\right.$ : Scheme 2 and Table 2, entries 1 and 2).

Table 2. Yields of the reaction of medium-sized 5-cycloalkynones 12 with inorganic and organic $\mathrm{O}$-centered radicals $\mathrm{XO}^{\bullet}$.

\begin{tabular}{|c|c|c|c|c|c|c|}
\hline \multirow{2}{*}{ Entry } & \multirow{2}{*}{12} & \multirow{2}{*}{$\mathbf{X}$} & \multirow{2}{*}{$\begin{array}{c}\text { Yield(\%) } \\
(13+14)\end{array}$} & \multicolumn{3}{|c|}{ Product ratio $(\%)^{[a]}$} \\
\hline & & & & $13 b$ & $13 c$ & 14 \\
\hline 1 & $\mathbf{a}$ & $\mathrm{NO}_{2}{ }^{[b]}$ & 13a: $77^{[\mathrm{c}]}$ & & & \\
\hline 2 & b & $\mathrm{NO}_{2}{ }^{[b]}$ & $74^{[\mathrm{c}]}$ & 43 & 57 & - \\
\hline 3 & b & $\mathrm{SO}_{3}^{-}$ & $52^{[\mathrm{d}]}$ & 43 & 43 & 14 \\
\hline 4 & c & $\mathrm{NO}_{2}{ }^{[\mathrm{b}]}$ & 13d: $11^{[\mathrm{c}]}$ & & & \\
\hline 5 & b & $\mathrm{H}$ & $82^{[\mathrm{d}, \mathrm{e}]}$ & 6 & 12 & 82 \\
\hline 6 & b & $\mathrm{RC}(\mathrm{O}) ; \mathrm{R}=\mathrm{Me}^{[\mathrm{f}]}$ & $43^{[\mathrm{d}, \mathrm{e}, \mathrm{g}]}$ & 5 & 6 & 89 \\
\hline 7 & b & $\mathrm{RC}(\mathrm{O}) ; \mathrm{R}=\mathrm{C}_{6} \mathrm{H}_{5}^{[\mathrm{f}]}$ & $57^{[\mathrm{d}, \mathrm{e}]}$ & 4 & 8 & 88 \\
\hline 8 & b & $\mathrm{RC}(\mathrm{O}) ; \mathrm{R}=4-\mathrm{MeC}_{6} \mathrm{H}_{4}{ }^{[\mathrm{f}]}$ & $93^{[\mathrm{d}, e]}$ & 5 & 5 & 90 \\
\hline 9 & b & $\mathrm{RC}(\mathrm{O}) ; \mathrm{R}=4-\mathrm{MeOC}_{6} \mathrm{H}_{4}^{[\mathrm{f}]}$ & $80^{[\mathrm{d}, \mathrm{e}]}$ & 6 & 9 & 85 \\
\hline 10 & b & $\mathrm{RC}(\mathrm{O}) ; \mathrm{R}=3-\mathrm{NO}_{2} \mathrm{C}_{6} \mathrm{H}_{4}^{[\mathrm{f}]}$ & $74^{[\mathrm{d}, \mathrm{e}]}$ & 10 & 29 & 61 \\
\hline 11 & b & $\mathrm{RC}(\mathrm{O}) ; \mathrm{R}=4-\mathrm{NO}_{2} \mathrm{C}_{6} \mathrm{H}_{4}^{[\mathrm{ff}]}$ & $85^{[\mathrm{d}, \mathrm{e}]}$ & 11 & 30 & 59 \\
\hline 12 & b & $\mathrm{RC}(\mathrm{O}) ; \mathrm{R}=4-\mathrm{FC}_{6} \mathrm{H}_{4}{ }^{[\mathrm{f}]}$ & $88^{[\mathrm{d}, e]}$ & 7 & 9 & 84 \\
\hline 13 & b & $\mathrm{ROC}(\mathrm{O}) ; \mathrm{R}=\mathrm{Me}^{[\mathrm{f}]}$ & $84^{[\mathrm{d}, e]}$ & 9 & 12 & 79 \\
\hline 14 & $\mathbf{b}$ & $\mathrm{ROC}(\mathrm{O}) ; \mathrm{R}=\mathrm{Ally} \mathrm{l}^{\mathrm{ff}]}$ & $75^{[\mathrm{d}, \mathrm{e}]}$ & 10 & 18 & 72 \\
\hline 15 & $\mathbf{b}$ & $\mathrm{ROC}(\mathrm{O}) ; \mathrm{R}=\mathrm{C}_{6} \mathrm{H}_{5}{ }^{[\mathrm{f}]}$ & $63^{[\mathrm{d}, \mathrm{e}]}$ & 15 & 34 & 51 \\
\hline
\end{tabular}


Table 2. Cont.

\begin{tabular}{lllllll}
\hline 16 & $\mathbf{b}$ & $\mathrm{ROC}(\mathrm{O}) \mathrm{C}(\mathrm{O}) ; \mathrm{R}=\mathrm{Et}[\mathrm{f}]$ & $48[\mathrm{~d}, \mathrm{e}, \mathrm{g}]$ & 10 & 17 & 73 \\
17 & $\mathbf{b}$ & $\mathrm{R} 2 \mathrm{NC}(\mathrm{O}) ; \mathrm{R}=\mathrm{Et}^{[\mathrm{f}]}$ & $75^{[\mathrm{d}, \mathrm{e}]}$ & 11 & 13 & 76 \\
18 & $\mathbf{b}$ & $\mathrm{R} ; \mathrm{R}=\mathrm{Me}^{[\mathrm{h}]}$ & $53^{[\mathrm{d}, \mathrm{e}]}$ & 6 & 49 & 45 \\
\hline
\end{tabular}

${ }^{[\mathrm{a}]}$ Ratio determined by GC; ${ }^{[\mathrm{b}]}$ Electrogenerated $\mathrm{NO}_{3}{ }^{\bullet} ;{ }^{[\mathrm{c}]}$ Preparative scale, isolated yield; ${ }^{[\mathrm{d}]}$ Analytical scale, GC yield with internal standard ( $n$-hexadecane); ${ }^{\mathrm{e}]}$ Yield with regard to the radical precursor (see text); ${ }^{[\mathrm{f}]}$ Radical precursor $3 ;{ }^{[\mathrm{g}]}$ Yield not optimized; ${ }^{[\mathrm{h}]}$ Radical precursor $\mathbf{5}$.

The mechanism, shown in Scheme 4 for the exemplary reaction of $\mathbf{1 2 b}$ (with $\mathrm{X}=\mathrm{NO}_{2}$ ), consists, after initial $\mathrm{NO}_{3} \bullet$ addition to the triple bond to yield the vinyl radicals $\mathbf{1 8 a} / \mathbf{b}$, of a transannular radical cyclization to the carbonyl group. The resulting isomeric allyloxyl radicals $\mathbf{1 9 a} / \mathbf{b}$ subsequently cyclize in a 3-exo fashion to the remaining $\mathrm{C}=\mathrm{C}$ double bond, and homolytic scission of the $\mathrm{O}-\mathrm{N}$ bond in $\mathbf{2 0 a} / \mathbf{b}$ finally yields the epoxy ketones $\mathbf{1 3 b} / \mathbf{c}$ and $\mathrm{NO}_{2} \bullet$. Because of the fast subsequent terminating fragmentation step (AM1 calculations revealed that the activation barrier for this homolytic scission is only $5.4 \mathrm{~kJ} \mathrm{~mol}^{-1}$ [29]), this reaction is one of the very rare example for an irreversible 3-exo cyclization of allyloxyl radicals to ultimately yield epoxides (see below).

The low yield in the radical cyclization of the larger cycloalkynone 12c (Table 2, entry 4) might be due to significant ring strain in the respective radical intermediates, which resulted in a poor overlap of the involved orbitals [32].

\section{Scheme 4}

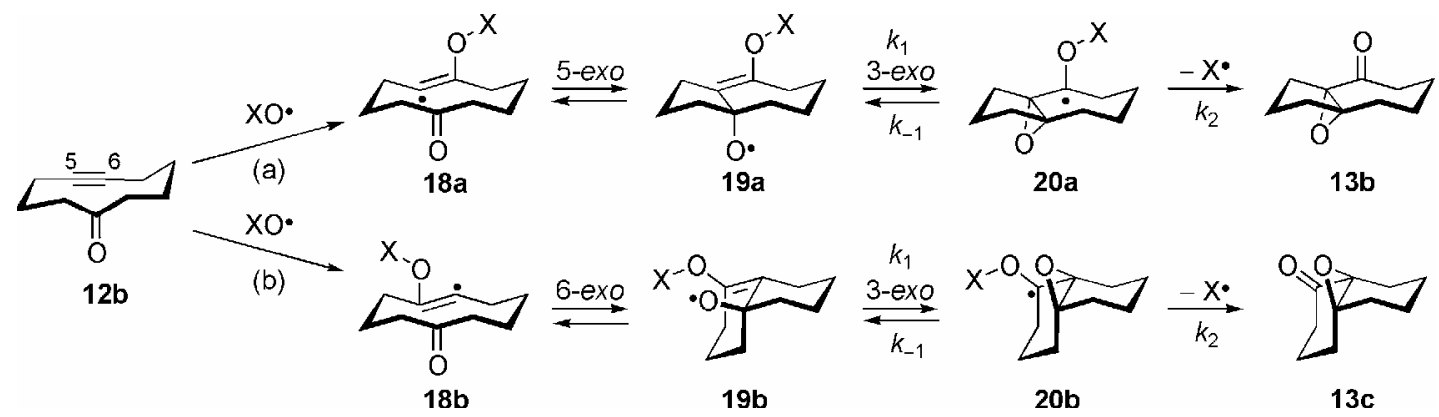

Similar to the mechanism shown in Scheme 3, also open-chain alkynes could be oxidatively cyclized through treatment with $\mathrm{NO}_{3}{ }^{\bullet}$. To promote intramolecular reactions, a reduction of the possible conformations in the alkyne is essential, which could be simply achieved, for example, by the introduction of cycloalkyl bridges. Thus, following radical addition to the less hindered site of the alkyne bond, alkynyl ethers of type $\mathbf{2 1}$ were oxidatively cyclized with excellent diastereoselectivity to the tetrasubstituted tetrahydrofurans of type 22 (Scheme 5) [33]. The yield of this cyclization significantly depended on the conditions of radical generation, which also demonstrated the instability 
of the radical intermediates towards oxidation. Whereas the electrochemical formation of $\mathrm{NO}_{3}{ }^{\bullet}$ requires high potentials at the electrodes [34], a general reduction of the oxidizing environment was possible using the photolysis of $\mathrm{CAN}$ as $\mathrm{NO}_{3}{ }^{\bullet}$ source, because it enables the dosage of the oxidizing radical precursor in high dilution. Under these conditions, the yield of cyclized products could be enhanced to $65 \%$ (with respect to the minor compound CAN) [35]. Under comparable conditions, also tetrasubstituted pyrrolidines of type $\mathbf{2 7}$ can be synthesized with good diastereoselectivity through $\mathrm{NO}_{3} \bullet$ induced cyclization of alkynyl amines such as $\mathbf{2 6}$ (Scheme 5) [36].

\section{Scheme 5}

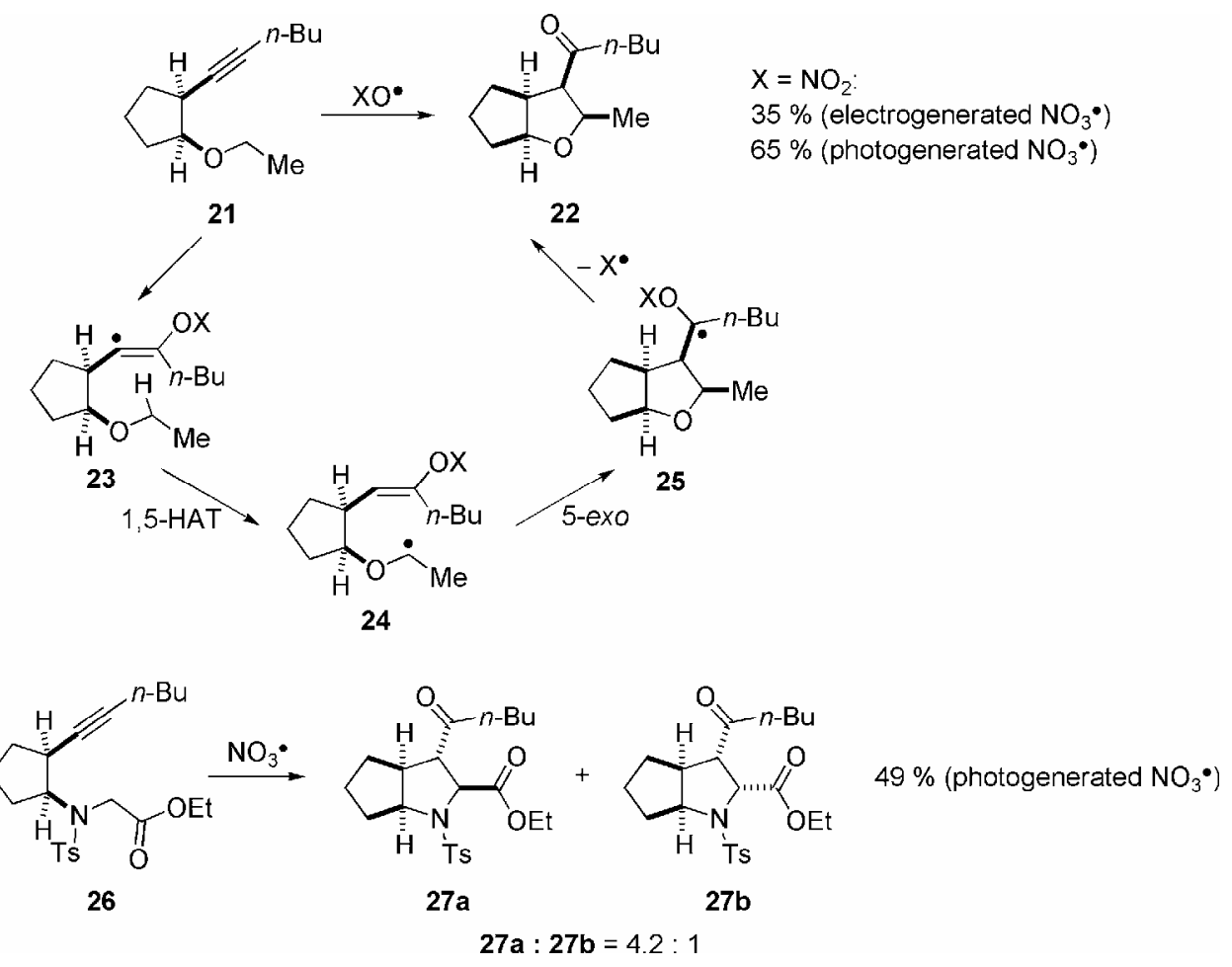

Mechanistic studies using deuterated homologues of 21 revealed that the 1,5-HAT is a strictly intramolecular process, which is, with a kinetic isotope effect $k_{\mathrm{H}} / k_{\mathrm{D}}=3$, also the rate determining step in this sequence [33]. This experimental observation could be theoretically verified by us using densitiy functional methods [37]. The stereoselectivity of this radical reaction is very likely determined in the subsequent 5-exo cyclization. We investigated the stereochemical aspects of the cyclization cascade using various homologues of $\mathbf{2 1}$ bearing cycloalkyl rings with both different size and stereochemistry and different substituents in the side chains [38]. With few but remarkable exceptions, the cyclizations proceeded with high to excellent diastereoselectivity according to the Beckwith-Houk transition state model for radical cyclizations, which is based on the minimization of 
steric interactions [1]. However, the exceptions lead us to the conclusion that additional electronic effects must also have a significant directing influence on the stereoselection in radical cyclizations. These effects are under current theoretical examination by us using ab initio and density functional calculations [37].

$\mathrm{SO}_{4}{ }^{{ }^{-}}$Radicals: $\mathrm{SO}_{4}{ }^{{ }^{-}}$is known to be a very strong one-electron oxidant with the unpaired electron on average located on oxygen. Whereas the mechanistic aspects of $\mathrm{SO}_{4}{ }^{{ }^{-}}$induced electron transfer reactions of alkenes or aromatic compounds have been thoroughly investigated [39-43], the property of $\mathrm{SO}_{4}{ }^{--}$to act as an $\mathrm{O}$ atom donor in its reactions with closed-shell compounds was never reported before. Various procedures for the synthesis of $\mathrm{SO}_{4}{ }^{-}$in solution were described in literature, but it turned out that for our purposes the Fenton redox system $\mathrm{Fe}^{\mathrm{II}} /$ peroxo disulfate was most appropriate to generate $\mathrm{SO}_{4}{ }^{\bullet-}$ on a preparative scale (Scheme 1.3) [44-47].

In order to elucidate the generality of the self-terminating, oxidative radical cyclization concept, the reaction of $9 \mathbf{a}$ with $\mathrm{SO}_{4}{ }^{--}$was chosen as representative model system (Scheme $2, \mathrm{X}=\mathrm{SO}_{3}{ }^{-}$). To our delight, it turned out that $\mathrm{SO}_{4}{ }^{{ }^{-}}$is obviously a very efficient $\mathrm{O}$ atom synthon, since the ketones 10a and 11 were obtained in $79 \%$ combined GC-yield (Table 1, entry 3). According to the mechanism in Scheme $3\left(\mathrm{X}=\mathrm{SO}_{3}{ }^{-}\right)$, the leaving group in this radical cyclization is $\mathrm{SO}_{3}{ }^{-}$, which shows that this novel cyclization cascade works also with charged radicals! The cleaved, reducing $\mathrm{SO}_{3}{ }^{-}{ }^{-}$did not interfere with intermediates or reaction products in this sequence to a measurable extent, so that the basic requirement for a self-terminating radical cyclization is fulfilled [48].

HO• Radicals: $\mathrm{HO}^{\bullet}$ is probably the radical with the highest reactivity at all, which reacts with organic compounds by either HAT or addition to $\pi$ systems rather than by direct electron transfer. Donation of its $\mathrm{O}$ atom to closed-shell compounds has not yet been reported in literature. Although various methods of $\mathrm{HO}^{\bullet}$ generation in solution are known, not all were suitable for our purposes. Finally, it turned out that photolysis of the thiopyridone $\mathbf{1}$ in acetonitrile was the best method to generate $\mathrm{HO}^{\bullet}$ on a preparative scale (Scheme 1.4) [49].

Considering an analog $\mathrm{OH}^{\bullet}$ induced self-terminating, oxidative radical cyclization as is shown in Scheme 3 (with $\mathrm{X}=\mathrm{H}$ ), homolytic scission of the relatively strong $\mathrm{O}-\mathrm{H}$ bond and release of a reactive $\mathrm{H}^{\bullet}$ in the final step must occur. The required energy for this fragmentation must be counterbalanced by the energy gained through formation of the stable carbonyl bond. To explore the principal ability of $\mathrm{OH}^{\bullet}$ to initiate and undergo this radical cyclization cascade, its reaction with cycloalkyne 9a was again chosen as model system (Scheme 2). Indeed, by fast trapping of $\mathrm{HO} \bullet$ through a roughly six-fold excess of $9 \mathrm{a}$ the isomeric ketones $\mathbf{1 0 a} / \mathbf{1 1}$ could be obtained in remarkable $63 \%$ combined yield (with regard to the minor radical precursor 1 , Table 1, entry 4) [50]. Lower excess or even stoichiometric concentrations of radical precursor and cycloalkyne or presence of the radical reaction inhibitor oxygen significantly reduced the yield. Thus, although $\mathrm{OH}^{\bullet}$ at first seemed to be an uncertain candidate, it appears, as if the synthetic potential of $\mathrm{OH}^{\bullet}$ has to be extended by its properties as an $\mathrm{O}$ 
atom synthon in this oxidative radical cyclization of alkynes. However, the fate of the released, highly reactive $\mathrm{H}^{\bullet}$ was not examined, but it may be assumed that, besides HAT from the solvent or from 9a, $\mathrm{H}^{\bullet}$ could initiate formation of further $\mathrm{HO} \bullet$ through addition at the thione moiety in $\mathbf{1}$, thus starting a radical-chain process (not shown). Principally, the latter reaction would not violate the concept "selftermination", since only new oxidizing $\mathrm{HO}^{\bullet}$ would be produced - in contrast to a $\mathrm{H}^{\bullet}$ induced HAT from the cycloalkyne.

\section{Other Oxygen-Centered Radicals}

The finding of this novel oxidative radical cyclization cascade, which is initiated by addition of inorganic $O$-centered radicals and radical anions $\mathrm{XO}^{\bullet}$ to alkynes and terminated by release of an unreactive part of the entering radical, encouraged us to look for further radical species possessing similar properties: (i) The unpaired electron being located on average on an oxygen atom, and (ii) a relatively stable leaving group $\mathrm{X}^{\bullet}$, which is cleaved after the radical cyclization, taking the unpaired electron. Hence, we wondered, whether not, despite all literature knowledge, also certain organic, $O$ centered radicals might be able to initiate and undergo self-terminating, oxidative radical cyclizations.

$\mathbf{R C}(\mathbf{O}) \mathbf{O}^{-}$Radicals: It is known that acyloxyl radicals, $\mathrm{RC}(\mathrm{O}) \mathrm{O}^{\bullet}$, could principally add to $\mathrm{C}=\mathrm{C}$ double bonds, but this addition reaction has to compete with their fast decarboxylation [14,51]. Interestingly, we were able to trap the acyloxyl radicals $4 \mathbf{a}$ (with $\mathrm{R}=\mathrm{Me}, \mathrm{C}_{6} \mathrm{H}_{5}$ or $4-\mathrm{MeOC}_{6} \mathrm{H}_{4}$, respectively) which were generated by photolyzing the respective Barton esters 3a (Scheme 1.5), prior to decarboxylation through addition to the $\mathrm{C} \equiv \mathrm{C}$ triple bond in 2.5 - 10-fold excess of cycloalkyne 9a, yielding the ketones $\mathbf{1 0 a} / \mathbf{1 1}$ in good to excellent yields (Table 1, entries 5-7) [52]. According to Scheme 3 , this cyclization cascade is terminated by cleavage of an acyl radical $\left[\mathrm{X}^{\bullet}=\mathrm{RC}(\mathrm{O})^{\bullet}\right]$. In order to evaluate, whether such a fragmentation is generally possible or whether another, yet unknown termination step must occur, we irradiated azo compound 28 [53], which lead to formation of cyclohexanone $\mathbf{3 0}$ in 33\% yield (GC), which should be formed through homolytic cleavage of the Oacyl bond in the intermediate 29 (Scheme 6) [52,54].

\section{Scheme 6}

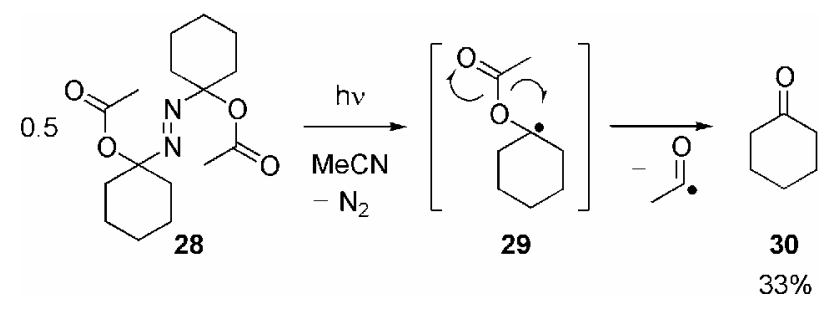


Since, as with the inorganic radicals, no measurable interfering reactions by the cleaved acyl radicals was observed, acyloxyl radicals represent the first purely "organic" radicals, which initiate and undergo self-terminating, oxidative radical cyclizations, in which they act as $\mathrm{O}$ atom synthon - a chemical property of acyloxyl radicals, which was never reported before!

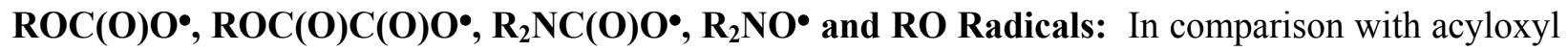
radicals, the tendency of (alkoxycarbonyl)oxyl radicals, $\mathrm{ROC}(\mathrm{O}) \mathrm{O}^{\bullet}$, to decarboxylate is less pronounced, but they are significantly more reactive with regard to intermolecular HAT and addition to $\pi$ systems [55-60]. In contrast to this, [(alkoxycarbonyl)acyl] oxyl radicals, $\mathrm{ROC}(\mathrm{O}) \mathrm{C}(\mathrm{O}) \mathrm{O}^{\bullet}$, are known to undergo two stepwise, very fast decarboxylations [61], and they are very versatile precursors for alkoxycarbonyl and alkyl radicals [62-65]. However, to our knowledge, their addition to $\pi$ systems prior to decarboxylation was not yet reported. Likewise, due to their rapid decarboxylation $[55,61]$, (carbamoyl)oxyl radicals, $\mathrm{R}_{2} \mathrm{NC}(\mathrm{O}) \mathrm{O}^{\bullet}$, are frequently used as precursors for $N$-centered radicals [6670]. Nitroxyl radicals, $\mathrm{R}_{2} \mathrm{NO} \mathrm{O}^{\bullet}$, are comparatively stable compounds and are widely applied as radical traps for mechanistic studies [71,72], or are used in synthesis, for example in free-radical "living" polymerizations [73].

However, can these radicals, like acyloxyl radicals and $\mathrm{NO}_{3}{ }^{\bullet}, \mathrm{SO}_{4}{ }^{--}$and $\mathrm{HO}$, respectively, also transfer an $\mathrm{O}$ atom to alkynes in a self-terminating, oxidative radical cyclization sequence? The reaction of 9 a was again chosen as model system, and $\mathrm{ROC}(\mathrm{O}) \mathrm{O}^{\bullet}, \mathrm{ROC}(\mathrm{O}) \mathrm{C}(\mathrm{O}) \mathrm{O}^{\bullet}, \mathrm{R}_{2} \mathrm{NC}(\mathrm{O}) \mathrm{O}^{\bullet}$ and $\mathrm{RO} \bullet$ were generated through photolysis of the corresponding precursors $\mathbf{3}$ and $\mathbf{5}$ (Scheme 1.5 and 1.6) in the presence of 9a. In all cases, formation of the bicyclic ketones 10a/11 was observed (Table 1, entries 8-16) [74]. As with $\mathrm{RC}(\mathrm{O}) \mathrm{O}^{\bullet}$, the outcome was significantly dependent on the concentration of the "radical scavenger" 9a, and by using a roughly three-fold excess of 9a, generally good to excellent yields of 10a/11 were obtained [75]. However, although the performance of the methoxyl radical, $\mathrm{MeO}^{\bullet}$, was less convincing on the first sight (Table 1, entry 16), this experiment revealed unequivocally that, surprisingly, even alkoxyl radicals can principally initiate and undergo selfterminating radical oxygenations, although reactive alkyl radicals must be acting as leaving group $\mathrm{X}^{\bullet}$. Experiments to improve the efficiency of alkoxyl radicals in this cyclization sequence are underway [76].

In the case of the (carbamoyl)oxyl radicals, $\mathrm{R}_{2} \mathrm{NC}(\mathrm{O}) \mathrm{O}^{\bullet} \mathbf{4 d}$, a strong dependence of reaction outcome on the substitution pattern at the nitrogen atom was apparent. Whereas the combined yield of $\mathbf{1 0 a} / \mathbf{1 1}$ was $89 \%$ in the case of the $N, N$-dialkylated species (Table 1 , entry 13 ), the yield in the case of the $N$-ethyl, $N$-phenyl substituted radical was clearly lower (Table 1, entry 15 ). We believe that the rate constant for decarboxylation of the latter, $k_{3}$, by which the $N$-centered, stable "benzyl-analog" radical 31 is formed, must be very fast and of the same order of magnitude as the rate constant for radical addition to 9a, $k_{4}$, leading to the vinyl radical 32 (Scheme 7). 


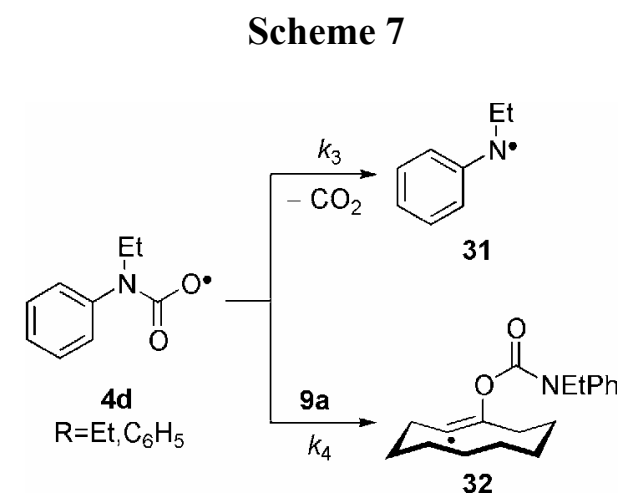

On the other hand, because of a lacking similar stabilization at the nitrogen atom, decarboxylation of the $N, N$-dialkylated (carbamoyl)oxyl radical $\mathrm{Et}_{2} \mathrm{NC}(\mathrm{O}) \mathrm{O}^{\bullet}$ might not be that fast, so that this radical can be efficiently trapped by addition to the alkyne triple bond. This result is the first experimental evidence that (carbamoyl)oxyl radicals have a certain, albeit short, lifetime. This is an important finding, since so far any attempt to spectroscopically detect (carbamoyl)oxyl radicals has been unsuccessful $[55,70]$.

Compared with the various $O$-centered radicals investigated by us so far, nitroxyl radicals, $\mathrm{R}_{2} \mathrm{NO}^{\bullet}$ $\mathbf{8}$, react only very slowly with closed-shell compounds, and the study of their behavior towards alkynes seemed to be a challenge. Their generation from the parent hydroxylamines 7 required potent oxidizing reagents, such as CAN (Scheme 1.7). Using the model reaction with 9a, moderate to satisfactory yields of the ketones $\mathbf{1 0 a} / \mathbf{1 1}$ were obtained, when either CAN or the hydroxylamine $\mathbf{7}$ was the minor compound (ca. 0.3 eq.), and the reaction was carried out under ultrasound treatment in the absence of light (Table 1, entries 17 and 18) [74,77,78]. It was important to use nitroxyl radicals with at least one $\mathrm{sp}^{2}$ center adjacent to nitrogen, since steric hindrance around the radical site significantly influenced the success of the anyway difficult reaction. The stable nitroxyl radical TEMPO $(2,2,5,5$ tetramethylpiperidine-1-oxyl), for example, did not react with 9a at all (not shown).

\section{Some Mechanistic Considerations}

So far, we have shown that self-terminating, oxidative radical cyclizations are obviously not a special reaction for a few selected radicals, but are rather a very general concept, which can be applied to various different inorganic and organic $O$-centered radicals and even radical anions. This has lead to the discovery of an entirely new chemical behavior of well-known radicals as $\mathrm{O}$ atom synthon. In order to expand this novel concept to the application of other, not necessarily $O$-centered radicals, it is important to know the driving force of this reaction.

We believe that the key step in the mechanism is the final homolytic cleavage of the $\mathrm{O}-\mathrm{X}$ bond in the radicals 17, 20 and 25, respectively (Schemes 3, 4 and 6) to yield $\mathrm{X}^{\bullet}$ and the ketones or epoxy ketones 10/11, 13 and 22 respectively [79]. Considering the mechanism shown in Scheme 4, it is 
important to note that the ring opening of unsubstituted oxiranylcarbinyl radicals is a very fast reaction with a rate constant of $k_{-1}>4 \times 10^{8} \mathrm{~s}^{-1}[80,81]$. The activation barrier of this process was determined to be $25 \mathrm{~kJ} \mathrm{~mol}^{-1}$ [82], thus suggesting a fast oxiranylcarbinyl - allyloxyl radical interconversion $[80,81]$. The finding that $\mathbf{1 3} \mathbf{b} / \mathbf{c}$ were formed in excellent overall yield in the reaction of $\mathbf{1 2 b}$ with $\mathrm{NO}_{3} \bullet$ shows that the final homolytic fragmentation should be an extremely fast process with $k_{2}>k_{-1}$, despite the fact that formation of $\mathrm{NO}_{2} \bullet$ is endothermic $\left[\Delta \mathrm{H}_{f}\left(\mathrm{NO}_{2} \bullet\right)=33.08 \mathrm{~kJ} \mathrm{~mol}^{-1}\right]$ [83].

When we performed the reaction of $\mathbf{1 2} \mathbf{b}$ with all other inorganic and organic $O$-centered radicals in this investigation (besides $\mathrm{NO}_{3}{ }^{\circ}$ ), the spiro diketone $\mathbf{1 4}$ appeared as a third reaction product (Scheme 2). In the case of all organic radicals and also $\mathrm{HO}^{\bullet}$, the amount of $\mathbf{1 4}$ contributed to up to about 80-90 $\%$ of the products formed, and the epoxy ketone $\mathbf{1 3 b}$ was unequivocally formed as minor product only (Table 2). Formation of $\mathbf{1 4}$ could proceed in competition the 3-exo cyclization of the allyloxyl radical, $19 b \rightarrow 20 b$, through its $\beta$-fragmentation $19 b \rightarrow 33$, subsequent 5 -exo cyclization $33 \rightarrow 34$ and final homolytic cleavage of the $\mathrm{O}-\mathrm{X}$ bond in $\mathbf{3 4}$ (Scheme 8) [84].

\section{Scheme 8}
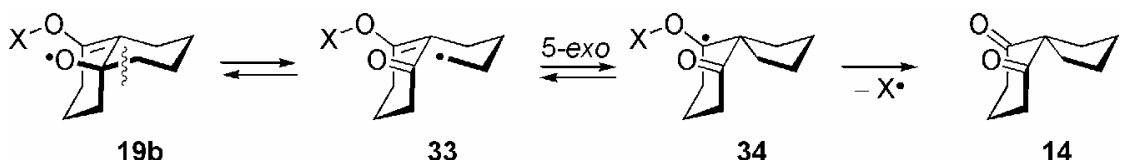

These observations led to the conclusion that the ability of $\mathrm{X}^{\bullet}$ to act as a leaving group was significantly lower, if $\mathrm{X}^{\bullet}=\mathrm{RC}^{\bullet}(\mathrm{O}), \mathrm{ROC}^{\bullet}(\mathrm{O}), \mathrm{ROC}(\mathrm{O}) \mathrm{C}^{\bullet}(\mathrm{O}), \mathrm{R}_{2} \mathrm{NC}^{\bullet}(\mathrm{O}), \mathrm{R}^{\bullet}$ or $\mathrm{H}^{\bullet}$ (see Scheme 3 ) and that a homolytic fragmentation according to $\mathbf{2 0} \rightarrow \mathbf{1 3}$ could not compete successfully with the cycloreversion $20 \rightarrow 19$, e.g. $k_{2}<k_{-1}$, so that their relative rates determine the product ratio [85].

Which factors actually determine the ease of the final homolytic cleavage leading to the release of $\mathrm{X}^{\bullet}$ and formation of the carbonyl group in the ketones $13 \mathrm{~b} / \mathbf{c}$ and 14 , respectively, should be discussed. If this reaction would be kinetically controlled, the activation barrier for the homolytic dissociation of the $\mathrm{O}-\mathrm{X}$ bond should be important. Because no data were available for the bond strengths in radicals of type 20, the bond dissociation energies must be discussed on the basis of the respective evenelectron systems [86]. As mentioned above, the activation barrier for the $\mathrm{O}-\mathrm{NO}_{2}$ bond cleavage in our systems was calculated to be very low [29]. This is in accordance with the relatively small energy required to cleave an $\mathrm{O}-\mathrm{N}$ bond in aliphatic nitrates, which is in the range of $160-170 \mathrm{~kJ} \mathrm{~mol}^{-1}$ [87-89]. In contrast to this, the dissociation of an ester bond according to $\mathrm{O}-\mathrm{C}(\mathrm{O}) \mathrm{R}$ requires around $370 \mathrm{~kJ} \mathrm{~mol}^{-}$ ${ }^{1}$ [90], and it may be assumed that the value is very similar in carbonates and carbamates. In a comparative order of magnitude are also the bond strengths in aliphatic ethers $\left(340 \mathrm{~kJ} \mathrm{~mol}^{-1}\right)$ [89]. The $\mathrm{O}-\mathrm{H}$ bond in aliphatic alcohols is still considerably stronger $\left(435 \mathrm{~kJ} \mathrm{~mol}^{-1}\right)[91,92]$. With these data in mind, comparison with the results in Table 2 revealed that the ratio of the epoxy ketones $\mathbf{1 3 a} / \mathbf{b}$ vs. spiro ketone 14 directly reflected the energy of the $\mathrm{O}-\mathrm{X}$ bond. It may be therefore suggested that 
homolytic cleavage of an $\mathrm{O}-\mathrm{S}$ bond and release of $\mathrm{SO}_{3}{ }^{--}$should be only slightly more difficult than cleavage of $\mathrm{NO}_{2}{ }^{\bullet}$, since only relatively low amounts of $\mathbf{1 4}$ were formed in the reaction of $\mathrm{SO}_{4}{ }^{-}$with 12b (Table 2, entry 3) [93]. In contrast to this, the heats of formation of the released radicals $\mathrm{X}^{\bullet}$, $\Delta \mathrm{H}_{f},\left(\mathrm{X}^{\bullet}\right)$, as far as they are known, did not lead to a correlation between the ratio $\mathbf{1 3 a} \mathbf{a} / \mathbf{b}$ vs. 14 (data not shown) [84]. It may be therefore concluded that the final homolytic cleavage and with this the entire radical cyclization cascade is a kinetically driven reaction. This finding will help us in our ongoing work to discover new reactions of well-known or yet unknown radicals.

The nearly equimolar amounts of the epoxy ketones $13 \mathbf{b} / \mathbf{c}$ formed in the reaction of $\mathbf{1 2 b}$ with either $\mathrm{NO}_{3}{ }^{\bullet}$ or $\mathrm{SO}_{4}{ }^{-}$reflected the ratio of the primary radical attack, which should occur with approximately the same probability at both sites of the $\mathrm{C} \equiv \mathrm{C}$ triple bond, since no apparent sterical hindrance exists. It seems reasonable to us that this should also be the case in the reaction of $\mathbf{1 2 b}$ with any other radical in this work. However, the generally high combined yield of $\mathbf{1 3 b} / \mathbf{c}$ and $\mathbf{1 4}$ in the reactions with the various radicals and the absence of any products arising from an initially formed vinyl radical 18a (see Scheme 4) lead to the suggestion that also the initial radical addition could be either completely reversible [94], or that the vinyl radicals $\mathbf{1 8 a}$ and $\mathbf{1 8 b}$ could isomerise, since a direct conversion 19a $\rightarrow$ 19b seems very unlikely. Such an isomerization could possibly proceed through a 1,2-migration (Scheme 9) in analogy to the process in $\beta$-(acetoxy)ethyl radicals, which was intensively described in literature [14,95]. The transition state could be either five- or three-membered (35 or $\mathbf{3 6}$, respectively), and both a concerted process with a delocalized radical (structures a) or a migration via an intimate radical anion-cation pair (structures b) could be imagined. However, whereas in the case of $\mathrm{X}=\mathrm{RC}(\mathrm{O})$, $\mathrm{ROC}(\mathrm{O}), \mathrm{ROC}(\mathrm{O}) \mathrm{C}(\mathrm{O})$, or $\mathrm{R}_{2} \mathrm{NC}(\mathrm{O})$, respectively, both a five- and three-membered transition state might be considered, the latter would be the only possibility, if $\mathrm{X}$ does not possess a $\pi$ system $\alpha$ to the transferred oxygen, e.g. alkyl or $\mathrm{H}$, respectively.

\section{Scheme 9}

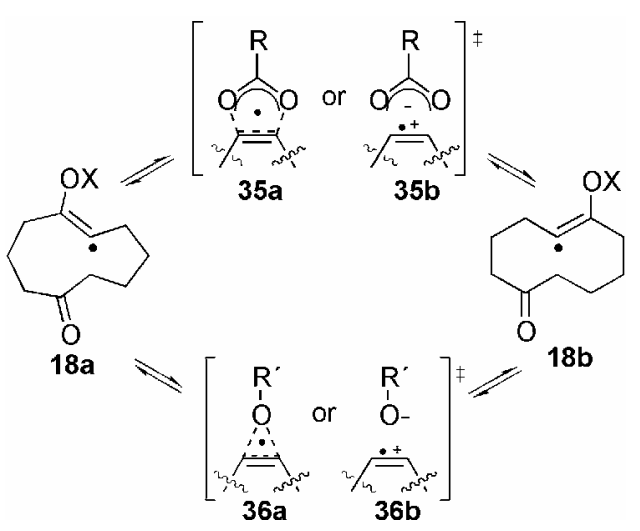




\section{Conclusions and Future Outlook}

One of the hitherto synthetic gaps in radical chemistry, the $\mathrm{C}-\mathrm{O}$ bond formation by intermolecular addition of $O$-centered radicals to alkynes, can be filled using the inorganic radicals of type $\mathrm{X}-\mathrm{O} \bullet$ with $\mathrm{X}=\mathrm{NO}_{2}, \mathrm{SO}_{3}{ }^{-}$and $\mathrm{H}$, respectively. As these radicals add to $\mathrm{C} \equiv \mathrm{C}$ triple bonds, they induce a selfterminating, oxidative radical cyclization cascade, which ends by homolytic fragmentation under release of a carbonyl compound and an unreactive leaving radical $\mathrm{X}^{\bullet}$, which can be either charged or uncharged and does not interfere by starting an own radical chain process. Thus, in contrast to classical radical chain chemistry, stoichiometric amounts of the oxidizing radicals are required. However, this is not a disadvantage, since the radical precursors are not toxic and can be either purchased or easily synthesized in high yields. Hence, the inorganic radicals $\mathrm{NO}_{3}{ }^{\bullet}, \mathrm{SO}_{4}{ }^{--}$and $\mathrm{HO}^{\bullet}$, respectively, can be considered as $\mathrm{O}$-atom synthon, and the oxidation of alkynes proceeds under very mild conditions with high stereoselectivities.

The overwhelming generality of this novel synthetic concept in radical chemistry is demonstrated by the finding that also many different types of organic $O$-centered radicals, e.g. acyloxyl radicals, $\mathrm{RC}(\mathrm{O}) \mathrm{O}^{\bullet}$, (alkoxycarbonyl)oxyl radicals, $\mathrm{ROC}(\mathrm{O}) \mathrm{O}^{\bullet}, \quad[($ alkoxycarbonyl)acyl]oxyl radicals, $\mathrm{ROC}(\mathrm{O}) \mathrm{C}(\mathrm{O}) \mathrm{O}^{\bullet}$, (carbamoyl)oxyl radicals, $\mathrm{R}_{2} \mathrm{NC}(\mathrm{O}) \mathrm{O}^{\bullet}$, alkoxyl radicals, $\mathrm{RO} \bullet$, and even the relatively unreactive nitroxyl radicals, $\mathrm{R}_{2} \mathrm{NO}$, react similarly with alkynes as $\mathrm{O}$-atom synthon in a selfterminating radical oxygenation sequence. This is a remarkable example for the discovery of novel reactions and chemical behaviors of rather well known organic radicals, which might not have been revealed without the inorganic examples. We are currently studying the extension of the concept of self-termination in radical chemistry by using other main group IV-VI centered radicals.

\section{Acknowledgments}

We wish to thank the Deutsche Forschungsgemeinschaft, Fonds der Chemischen Industrie, Dr. Otto Röhm-Gedächtnisstiftung, Deutscher Akademischer Austauschdienst, Studienstiftung des deutschen Volkes and the Universität Kiel for financial support.

\section{References and Notes}

1. Curran, D. P.; Porter, N. A.; Giese, B. Stereochemistry of Radical Reactions; VCH: Weinheim, New York, Basel, Cambridge, Tokyo, 1996.

2. A recent compilation is given in: Linker, T.; Schmittel, M. Radikale and Radikalionen in der Organischen Synthese; Wiley-VCH: Weinheim, New York, Chichester, Brisbane, Singapore, Toronto, 1998.

3. Giese, B. Radicals in Organic Synthesis: Formation of Carbon-Carbon Bonds; Pergamon: Oxford, 1986. 
4. Baguley, P. A.; Walton, J. C. Angew. Chem. 1998, 110, 3272-3283; Angew. Chem. Int. Ed. Engl. 1998, 37, 3072-3082.

5. Studer, A. Chem. Eur. J. 2001, 7, 1159-1164.

6. Olivier, C.; Renaud, P. Angew. Chem. 2000, 112, 946-949; Angew. Chem. Int. Ed. Engl. 2000, 39, 925-928.

7. Hartung, J.; Kneuer, R.; Špehar, K. Chem. Commun. 2001, 799-800.

8. Mikami, S.; Fujita, K.; Nakamura, T.; Yorimitsu, H.; Shinokubo, H.; Matsubara, S.; Oshima, K. Org. Lett. 2001, 3, 1853-1855.

9. Hartung, J.; Gottwald, T.; Špehar, K. Synthesis 2002, 1469-1498; and cited refs.

10. Hartung, J. Eur. J. Org. Chem. 2001, 619-632; and cited refs.

11. Walling, C.; Clark, R. T. J. Am. Chem. Soc. 1974, 96, 4530-4534.

12. Walling, C.; El-Taliawi, G. J. Am. Chem. Soc. 1973, 95, 848-850.

13. Bottle, S.; Busfield, W. K.; Jenkins, I. D.; Skelton, B. W.; White, H. A.; Rizzardo, E.; Solomon, D. H. J. Chem. Soc., Perkin Trans. 2 1991, 1001-1007.

14. Fossey, J.; Lefort, D.; Sorba, J. Free Radicals in Organic Chemistry; Masson: Paris, 1995.

15. Waters, W. A. The Chemistry of Free Radicals; $2^{\text {nd }}$ ed., Oxford University Press, 1950.

16. Weissermel, K.; Arpe, H.-J. Industrial Organic Chemistry; $2^{\text {nd }}$ ed., VCH: Weinheim, 1993.

17. H. Meier, Synthesis 1972, 235-253.

18. Fokin, A. A.; Peleshanko, S. A.; Gunchenko, P. A.; Gusev, D. V.; Schreiner, P. R. Eur. J. Org. Chem. 2000, 3357-3362.

19. Grossi, L.; Strazzari, S. J. Org. Chem. 1999, 64, 8076-8079.

20. Tomat, R.; Rigo, A. J. Appl. Electrochem. 1986, 16, 8-14.

21. Mella, M.; Freccero, M.; Soldi, T.; Fasani, E.; Albini, A. J. Org. Chem. 1996, 61, 1413-1422.

22. Sulpizio, A.; Mella, M.; Albini, A. Tetrahedron 1989, 45, 7545-7552.

23. Shono, T.; Yamamoto, Y.; Takigawa, K.; Maekawa, H.; Ishifune, M.; Kashimura, S. Chem. Lett. 1994, 1045-1048.

24. Shono, T.; Soejima, T.; Takigawa, K.; Yamaguchi, Y.; Maekawa, H. Kashimura, S. Tetrahedron Lett. 1994, 35, 4161-4164.

25. Shono, T.; Chuankamnerdkarn, M.; Maekawa, H.; Ishifune, M.; Kashimura, S. Synthesis 1994, 895-897.

26. Baciocchi, E.; Del Giacco, T.; Rol, C.; Sebastiani, G. V. Tetrahedron Lett. 1985, 26, 541-544.

27. Baciocchi, E.; Del Giacco, T.; Rol, C.; Sebastiani, G. V. Tetrahedron Lett. 1985, 26, 3353-3356.

28. Baciocchi, E.; Del Giacco, T.; Sebastiani, G. V. Tetrahedron Lett. 1987, 28, 1941-1944.

29. Wille, U.; Plath, C. Liebigs Ann./Recueil 1997, 111-119.

30. Correctly, by taking both possible directions of enumeration in the carbocyclic ring into account, the transannular 1,5-HAT of $\mathbf{1 5}$ to $\mathbf{1 6 a}$ should be considered as a 1,5/1,7-HAT. By analogy, the reactions $16 \mathbf{a} \rightarrow \mathbf{1 7 a}$ and $\mathbf{1 6} \mathbf{b} \rightarrow \mathbf{1 7 b}$ should be termed as 5-exo/7-endo and 6-exo/6-endo 
cyclizations, respectively. For the sake of clarity the nomenclature of these transannular radical reactions is based on the most probable process; see ref. [14], p. 52.

31. Due to the electron withdrawing character of the carbonyl oxygen, a $\mathrm{C}=\mathrm{O}$ double bond in $\mathbf{1 2}$ is sufficiently electron deficient, so that addition of the electrophilic $\mathrm{NO}_{3} \bullet$ cannot occur. In the case of a $\mathrm{C}=\mathrm{C}$ double bond competition experiments had revealed that at least two electron withdrawing substituents are required to direct the initial $\mathrm{NO}_{3} \bullet$ attack regioselectively at the alkyne site: Stademann, A. Diploma Thesis, Universität Kiel (Germany), 2000.

32. Plath, C. Diploma Thesis, Universität Kiel (Germany), 1997.

33. Wille, U.; Lietzau, L. Tetrahedron 1999, 55, 10119-10134.

34. Estimated value for the redox couple $\mathrm{NO}_{3} \bullet / \mathrm{NO}_{3}^{-}: \mathrm{E}^{0}=2.0 \mathrm{~V}$ vs. SCE (in MeCN): Baciocchi, E.; Del Giacco, T.; Murgia, S. M.; Sebastiani, G. V. Chem. Commun. 1987, 1246-1248.

35. Lietzau, L.; Wille, U. Heterocycles 2001, 55, 377-380.

36. Stademann, A.; Wille, U. manuscript in preparation.

37. Dreessen, T.; Wille, U. manuscript in preparation.

38. Wille, U.; Lietzau, L. Tetrahedron 1999, 55, 11465-11474.

39. Davies, M. J.; Gilbert, B. C. J. Chem. Soc., Perkin Trans. 2 1984, 1809-1815.

40. Niehaus, H.; Hildenbrand, K. J. Chem. Soc., Perkin Trans. 2 2000, 947-952.

41. Walling, C.; Zhao, C.; El-Taliawi, G. M. J. Org. Chem. 1983, 48, 4910-4914.

42. Deeble, D. J.; Schuchmann, M. N.; Steenken, S.; von Sonntag, C. J. Phys. Chem. 1990, 94, 81868192.

43. Lomoth, R.; Naumov, S.; Brede, O. J. Phys. Chem. A 1999, 103, 6571-6579; and cited refs.

44. Minisci, F.; Citterio, A. Acc. Chem. Res. 1983, 16, 27-32.

45. Walling, C.; Camaioni, D. M. J. Am. Chem. Soc. 1975, 97, 1603-1604.

46. Walling, C.; Camaioni, D. M.; Kim, S. S. J. Am. Chem. Soc. 1978, 100, 4814-4818.

47. Effenberger, F.; Kottmann, H. Tetrahedron 1985, 41, 4171-4182.

48. Wille, U. Org. Lett. 2000, 2, 3485-3488.

49. Adam, W.; Ballmeier, D.; Epe, B.; Grimm, G. N.; Saha-Möller, C. R. Angew. Chem. 1995, 107, 2326-2328; Angew. Chem. Int. Ed. Engl. 1995, 34, 2156-2158.

50. Wille, U. Tetrahedron Lett. 2002, 43, 1239-1242.

51. Giese, B. In Houben-Weyl, Methoden der Organischen Chemie, Band E 19a, C-Radikale; Regitz, M; Giese, B., Eds.; Georg Thieme Verlag: Stuttgart, New York, 1989, p 140.

52. Wille, U. J. Am. Chem. Soc. 2002, 124, 14-15.

53. Benzing, E. Angew. Chem. 1960, 72, 709; and cited refs.

54. Since the final fragmentation step is expected to be the same, the yield of $\mathbf{3 0}$ appears to be too low compared with the yields of $\mathbf{1 0 a} / \mathbf{1 1}$ obtained in the reaction of the various $\mathrm{RC}(\mathrm{O}) \mathrm{O}^{\bullet}$ with $\mathbf{9 a}$. This discrepancy may be explained by the different reaction conditions. Whereas $\mathbf{1 0 a} / \mathbf{1 1}$ are generated by unimolecular fragmentation of highly diluted $17 \mathbf{a} / \mathbf{b}$, irradiation of 28 leads to formation of two molecules of $\mathbf{2 9}$ in close vicinity or even in the same solvent cage. 
Recombination 29 or other bimolecular reactions may be considered to compete with its fragmentation.

55. Chateauneuf, J.; Lusztyk, J.; Maillard, B.; Ingold, K. U. J. Am. Chem. Soc. 1988, 110, 6727-6731.

56. Edge, D. J.; Kochi, J. K. J. Am. Chem. Soc. 1973, 95, 2635-2643.

57. Korth, H. G.; Chateauneuf, J.; Lusztyk, J.; Ingold, K. U. J. Am. Chem. Soc. 1988, 110, 5929-5931.

58. Beckwith, A. L. J.; Hay, B. P. J. Am. Chem. Soc. 1988, 110, 4415-4416.

59. Beckwith, A. L. J.; Hay, B. P. J. Am. Chem. Soc. 1989, 111, 230-234.

60. Van Sickle, D. E. J. Org. Chem. 1969, 34, 3446-3451.

61. To our knowledge, absolute rate data for these processes were not determined.

62. Togo, H.; Fuji, M.; Yokoyama, M. Bull. Chem. Soc. Jpn. 1991, 64, 57-67.

63. Bucher, G.; Halupka, M.; Kolano, C.; Schade, O.; Sander, W. Eur. J. Org. Chem. 2001, 545-552.

64. Barton, D. H. R.; Crich, D. J. Chem. Soc., Perkin Trans. 1, 1986, 1603-1611.

65. Simakov, P. A.; Martinez, F. N.; Horner, J. H.; Newcomb, M. J. Org. Chem. 1998, 63, 1226-1232.

66. Newcomb, M.; Kumar, M. U.; Boivin, J.; Crépon, E.; Zard, S. Z. Tetrahedron Lett. 1991, 32, 4548.

67. Musa, O. M.; Horner, J. H.; Shahin, H.; Newcomb, M. J. Am. Chem. Soc. 1996, 118, 3862-3868.

68. Danen, W. C.; West, C. T.; Kensler, T. T. J. Am. Chem. Soc. 1973, 95, 5716-5724.

69. Esker, J. L.; Newcomb, M. J. Org. Chem. 1994, 59, 2779-2786.

70. Burdi, D.; Aveline, B. M.; Wood, P. D.; Stubbe, J.; Redmond, R. W. J. Am. Chem. Soc. 1997, 119, 6457-6460.

71. Hageman, H. J.; Oosterhoff, P.; Overeem, T.; Verbeek, J. J. Photochem. Photobiol. A: Chem. 1997, 110, 17-21.

72. Albéniz, A. C.; Espinet, P.; López-Fernández, R.; Sen, A. J. Am. Chem. Soc. 2002, 124, 1127811279.

73. Benoit, D.; Chaplinski, V.; Braslau, R.; Hawker, C. J. J. Am. Chem. Soc. 1999, 121, 3904-3920.

74. Jargstorff, C.; Wille, U. Eur. J. Org. Chem. 2003, 3173-3178.

75. The reason for the lower yield of $\mathbf{1 0 a} / \mathbf{1 1}$ obtained using thiazolethiones $\mathbf{5}$ as radical precursor is unclear. It was reported that the photoproducts arising from photolysis of thiazolethiones undergo a complicated chemistry: Adam, W.; Hartung, J.; Okamoto, H.; Marquardt, S.; Nau, W. M.; Pischel, U.; Saha-Möller, C. R.; Špehar, K. J. Org. Chem. 2002, 67, 6041-6049.

76. Gregor, J.; Azhar, I.; Wille, U. to be published.

77. GC-MS analysis revealed that in the reaction of the nitroxyl radicals with 9a small amounts of trans-10a and, presumably, trans-11 were also formed. It is believed that these compounds result from a subsequent acid-catalyzed isomerization of $\mathbf{1 0 a} / \mathbf{1 1}$, since the CAN mediated oxidation of hydroxylamines in acetonitrile is accompanied by production of equimolar amounts of protons.

78. Absence of light was essential to avoid generation of $\mathrm{NO}_{3}{ }^{\bullet}$ from $\mathrm{CAN}$ through a photo-induced electron transfer (Scheme 1.2). 
79. Most of the radicals used in these investigations were also tested in their reaction with open-chain alkynes of type 21 (see Scheme 5).

80. Laurie, D.; Nonhebel, D. C.; Suckling C. J.; Walton, J. C. Tetrahedron 1993, 49, 5869-5872.

81. Krishnamurthy V.; Rawal, V. H. J. Org. Chem. 1997, 62, 1572-1573.

82. The reversibility of allyloxyl radical formation was considered by: Ziegler F. E.; Petersen, A. K. J. Org. Chem. 1994, 59, 2707-2714.

83. Handbook of Chemistry and Physics, 63 ${ }^{\text {rd }}$ ed.; CRC Press: Boca Raton, Florida, 1982.

84. Wille, U.; Jargstorff, C. J. Chem. Soc., Perkin Trans. 1 2002, 1036-1041.

85. Theoretically, further $\beta$-fragmentation pathways other than that shown in Scheme 8 are possible in both isomeric allyloxyl radicals $19 \mathbf{a} / \mathbf{b}$. However, subsequent cyclizations would involve kinetically unfavourable 5-endo, 6-endo or 4-exo steps (see refs. [1,2,14]), and no products arising from such reactions were observed; see [84].

86. However, it might be expected that the energy required for cleavage of the $\mathrm{O}-\mathrm{X}$ bond in a radical of type $\mathrm{C}^{\bullet}(\mathrm{O})-\mathrm{X}$ is different from that in an even-electron system, but the general trend should be unaffected.

87. Luft, N. W. Z. Elektrochem. 1956, 60, 94-100.

88. Batt L.; McCulloch, R. D. Int. J. Chem. Kinet. 1976, 8, 491-500.

89. Orlov, Y. D.; Lebedev, Y. A. Bull. Acad. Sci. USSR Div. Chem. Sci. (Engl. Transl.) 1984, 33, 1227.

90. Gray P.; Williams, A. Trans. Faraday Soc. 1959, 55, 760-777.

91. Batt L.; McCulloch, R. D. Int. J. Chem. Kinet. 1976, 8, 911-933.

92. Mihalick, J. E.; Gatev, G. G.; Brauman, J. I. J. Am. Chem. Soc. 1996, 118, 12424-12431.

93. No literature data for the homolytic scission of an $\mathrm{O}-\mathrm{S}$ bond in organic sulfates were available.

94. A reversible addition of a tin-centered radical to the $\mathrm{C} \equiv \mathrm{C}$ triple bond in $\mathbf{1 2 b}$ was proposed: Baldwin, J. E.; Adlington R. M.; Robertson, J. Tetrahedron 1991, 47, 6795-6812.

95. Zipse, H.; Bootz, M. J. Chem. Soc., Perkin Trans. 2 2001, 1566-1572; and cited refs.

2004 by MDPI (http://www.mdpi.org). Reproduction is permitted for noncommercial purposes. 